\section{Predictors of intentional intoxication using decision tree modeling analysis: a retrospective study}

\author{
Eun Seok $\mathrm{Oh}^{1}$, Jae Hyung Choi', Jung Won Lee', Su Yeon Park ${ }^{2}$ \\ 'Department of Emergency Medicine, Soonchunhyang University College of Medicine, Cheonan, Korea \\ ${ }^{2}$ Department of Biostatistics, Soonchunhyang University Hospital, Seoul, Korea
}

Objective The suicide rate in South Korea is very high and is expected to increase in coming years. Intoxication is the most common suicide attempt method as well as one of the common reason for presenting to an emergency medical center. We used decision tree modeling analysis to identify predictors of risk for suicide by intentional intoxication.

Methods A single-center, retrospective study was conducted at our hospital using a 4-year registry of the institute from January 1, 2013 to December 31, 2016. Demographic factors, such as sex, age, intentionality, therapeutic adherence, alcohol consumption, smoking status, physical disease, cancer, psychiatric disease, and toxicological factors, such as type of intoxicant and poisoning severity score were collected. Candidate risk factors based on the decision tree were used to select variables for multiple logistic regression analysis.

Results In total, 4,023 patients with intoxication were enrolled as study participants, with 2,247 (55.9\%) identified as cases of intentional intoxication. Reported annual percentages of intentional intoxication among patients were 628/937 (67.0\%), 608/1,082 (56.2\%), 536/1,017 (52.7), 475/987 (48.1\%) from 2013 to 2016. Significant predictors identified based on decision tree analysis were alcohol consumption, old age, psychiatric disease, smoking, and male sex; those identified based on multiple regression analysis were alcohol consumption, smoking, male sex, psychiatric disease, old age, poor therapeutic adherence, and physical disease.

Conclusion We identified important predictors of suicide risk by intentional intoxication. A specific and realistic approach to analysis using the decision tree modeling technique is an effective method to determine those groups at risk of suicide by intentional intoxication.

Keywords Decision support techniques; Intoxication; Suicide

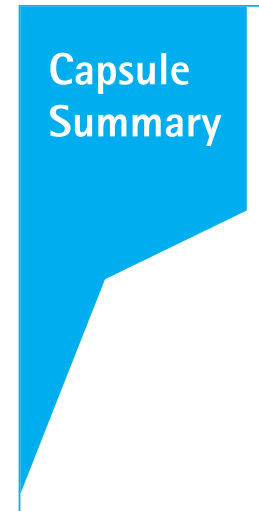

What is already known

The suicide rate in Korea is very high and it is very difficult to accurately predict the groups at risk of suicide. Previous studies have reported that suicide attempts are highest among elderly adults, men, and people with cancer or physical disease. However, these studies included random samples with the intention to verify risk of intentional intoxication.

\section{What is new in the current study}

In this study, we used adjusted data mining analysis to determine groups at risk for intentional intoxication through targeting all intoxication patients in the emergency medical department. Old age, psychiatric disease, smoking, and male sex were found to be the main factors that predict risk of intentional intoxication.
eISSN: 2383-4625

Received: September 152017

Revised: November 162017

Accepted: November 302017

Correspondence to: Jae Hyung Choi Department of Emergency Medicine, Soonchunhyang University College of Medicine, 31 Suncheonhyang 6-gil, Dongnam-gu, Cheonan 31151, Korea E-mail:emracoon@gmail.com ORCID https://orcid.org/0000-0002-4105-2574

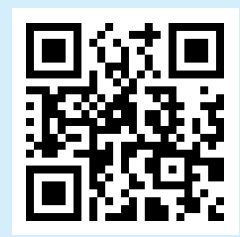

How to cite this article:

Oh ES, Choi JH, Lee JW, Park SY. Predictors of intentional intoxication using decision tree modeling analysis: a retrospective study. Clin Exp Emerg Med 2018;5(4):230239.

This is an Open Access article distributed under the terms of the Creative Commons Attribution Non-Commercial License (http:// creativecommons.org/licenses/by-nc/4.0/). 


\section{INTRODUCTION}

Suicide is a social phenomenon that has a great effect on society as well as the families of victims. Even after surviving a suicide attempt, suicidal individuals are often willing to make repeated attempts using more fatal methods. ${ }^{1-3}$ The World Health Organization has proposed useful public health actions targeting individuals at risk of suicide that could be useful to decrease suicide death rates. ${ }^{4}$ Suicide is influenced by various factors, and it is very difficult to accurately predict the populations at risk of suicide. ${ }^{5}$ Based on the findings of one study, 29\% of people with suicidal ideation attempted suicide; however, a national survey from 2007 to 2012 in South Korea reported that only 5.6\% of people with suicidal ideation attempted suicide. ${ }^{6,7}$ Moreover, in another survey, findings on risk factors related to suicidal ideation failed to predict the frequency of suicide attempts. ${ }^{8}$ Thus, the use of random-sampling surveys seems unlikely to effectively predict highrisk groups for suicide attempts.

Decision tree modeling analysis is a data mining method that is used to explore, extract, and model hidden knowledge, unexpected patterns, and new rules as well as relationships, patterns, and rules in massive data sets. This method uses a tree structure for classifying or predicting processes, to enable researchers to easily understand processes and easily interpret the results. Decision tree analysis is also useful for predicting risk groups by identifying hidden patterns rather than simply predicting risk factors in multiple logistic regression analysis. ${ }^{9-12}$

Intoxication is the most common suicide attempt method, as well as one of the common reason for presenting to emergency medical centers. ${ }^{13-17}$ Findings on the factors influencing suicide ideation, general characteristics of intentional intoxication among patients, and some clinical findings have been reported in South Korean and international studies. However, findings on the predictors of risk for intentional intoxication among actual poisoning victims are lacking. Hence, we examined the factors influencing intentional intoxication among patients in the emergency room using multiple logistic regression and decision tree modeling analyses, and extracted groups at risk for intentional intoxication by combining risk factors.

\section{METHODS}

The study protocol and design were reviewed and approved by the Institutional Review Board of Soonchunhyang University Cheonan Hospital (SCHCA 2017-07-013-001). Informed consent was waived from the Institutional Review Board because of the retrospective design of the study.
This study used a retrospective study design to obtain demographic and toxicologic characteristics of patients with intoxication who presented to the emergency medical center of Soonchunhyang University Cheonan Hospital (a tertiary medical center) in South Korea during a 4-year period from January 1, 2013 to December 3, 2016. The Pesticide Intoxication Institute (PSI) assigns patients to this emergency medical center, which has the highest number of patients under treatment for intoxication in South Korea. Intoxication is defined as exposure to intoxicants whereby the recommended dose of drugs is exceeded, or inappropriate symptoms occur with the appropriate recommended dose.

We collected patient information from the intoxication patient registry of the PSI from 2013 to 2016. We obtained information on demographic characteristics including sex, age, intentionality, therapeutic adherence, alcohol consumption, smoking status, physical disease, cancer, psychiatric disease, and toxicologic factors (such as the type of intoxicant), amount of poisoning, vital signs, Acute Physiology and Chronic Health Evaluation score, Glasgow coma scale score, poisoning severity score (PSS), hospitalization period, and treatment results. Intentionality was defined in the case of clear suicidal intention, based on a statement of the patient or their guardian. Alcohol consumption was determined by blood ethanol level measurement performed by PSI staff; smoking referred to the current smoking status. Obesity, hypertension, diabetes, renal disease, and daily activity limitation were included in the category of physical disease. All types of incurable cancer were included in the category of cancer. Psychiatric disease was defined as patients who received at least one psychiatric medical service. Poor therapeutic adherence was defined as the refusal of testing or treatment and not following instructions of the medical team.

There were seven intoxicant component categories: pesticides, nonprescription drug, prescription, household chemicals, industrial chemicals, inhalation agents, and plants. When intoxication was caused by multiple substances, classification was based on the most toxic among all the substances detected. If the toxicity level was difficult to ascertain, the substance most closely related to the patient's symptoms was considered the main intoxicant.

Substances categorized as pesticides included pesticides, herbicides, germicides, rodenticides, spreaders, and additives (such as surfactants). Nonprescription substances comprised antipyretics, analgesics, nonprescription sleeping pills, and nonprescription sedatives. Prescription drugs included cardiovascular medications, antipsychotics, antianxiety drugs, antidepressants, and mood stabilizers. Household chemicals included antiseptics, germicides, deodorants, corrosive agents, and nicotine. Industrial chemicals 
comprised hydrocarbon compounds, cyanide, and hydrogen sulfide. Carbon monoxide and butane gas were considered inhalation agents; plants included Phytolacca, motherwort, mushrooms, and tetrodotoxin.

For descriptive analysis, means with standard deviation or numbers and percentages were reported. The chi-square test or Fisher exact test was used to analyze categorical variables, and the Student t-test was performed for continuous variables. Multiple logistic regression with backward selection was used to identify the risk factors for intentionality, PSS, and therapeutic adherence. Odds ratios and 95\% confidence intervals were calculated to estimate the effect size of each risk factor. All tests were two-tailed, and a P-value $<0.05$ was considered statistically significant. To establish the prediction model, we carried out decision tree model analysis using R ver. 3.0.1 (R Foundation for Statistical Computing, Vienna, Austria). Chi-squared automatic interaction detection (CHAID), classification and regression tree (CART), and C50 methods were used to fit the model. Candidate risk factors based on the decision tree were used as selected variables in multiple logistic regression analysis. The receiver operating characteristic curve was used to evaluate the models and variable importance values were calculated to represent the percentage of mean decrease in misclassification. CHAID was used to extract results with the highest area under the curve values (CHAID $=0.800, C 50=0.798$, CART $=0.771)$.

\section{RESULTS}

\section{General characteristics of intoxication patients}

During the study period, 274,669 patients presented to the emergency medical center, with a total of 4,325 (1.57\%) poisoning victims. Among these, data of 4,023 (1.46\%) patients were analyzed. We excluded patients whose status could not be determined, such as those who did not reveal any information about suicide attempts and those who denied a suicide attempt. Cases of possible food poisoning and those with missing patient information were also excluded.

Table 1 lists the demographic and clinical characteristics of patients with and without intentional intoxication in this study. There were significant differences between the two groups with respect to rate of alcohol consumption, smoking, physical disease, cancer, psychiatric disease, PSS, and therapeutic adherence. The type of intoxicant also showed significant differences between the groups.

There were significant differences in the rates of intoxication between groups with unintentional and intentional intoxication, with a decreasing trend during the 4-year period (Table 1). How- ever, no significant differences were observed between the two groups regarding the time of day.

For daily and weekday/weekend rates, significant differences were found between the groups; there were lower weekend rates for the group with intentional intoxication, compared with the unintentional intoxication group (Table 1). Annual intoxicant rates differed significantly between the groups (Table 2). Pesticides were the most frequently used intoxication during the 4 years, except for 2016.

\section{Multiple logistic regression results for intentionality, PSS and therapeutic adherence}

Male sex, elderly age, alcohol consumption, smoking, physical disease, psychiatric disease, and poor therapeutic adherence were extracted as independent predictors of intentional intoxication. As for intoxicant substances, with prescription drugs as the reference, pesticides and nonprescription substances remained as predictors of intentional intoxication (Table 3).

Elderly age, alcohol consumption, smoking, physical disease, psychiatric disease, and intentionality were extracted as independent predictors of severe poisoning symptoms (PSS of more than 3 points). With prescription drugs as the reference, plants and pesticides remained as predictors of severe poisoning symptoms (Table 4).

Intentionality and alcohol consumption were extracted as independent predictors of poor therapeutic adherence. With prescription drugs as the reference, nonprescription substances remained as a predictor of poor therapeutic adherence (Table 5).

\section{Decision tree analysis}

The importance of the variables in the decision tree modeling was based on a CHAID algorithm. With the entire importance assumed to be $100 \%$, the importances of alcohol consumption, smoking, physical disease, elderly age, psychiatric disease, male sex, poor therapeutic adherence, and weekends were $34.1 \%$, $16.5 \%, 13.8 \%, 13.0 \%, 11.9 \%, 7.3 \%, 3.2 \%$, and $0.3 \%$, respectively. Five predictive variables were automatically extracted, and the analysis result was a tree consisting of a total six terminal nodes (leaves). At the root node of the tree were a total of 4,023 intoxication patients with a $56 \%$ risk of intentional intoxication. For all poisoning victims, alcohol consumption was selected as the first splitting variable. In the case of alcohol consumption, the intentional intoxication risk increased from 55.8\% to 86.6\% (about 1.55 times greater [group 1]). With no alcohol consumption, intentional intoxication risk decreased to $42.0 \%$ (about 1.32 times lower). Among patients with no alcohol consumption, age was selected as the second splitting variable. Among elderly patients 
Table 1. Characteristics of intoxication and their association with intentionality $(n=4,023)$

\begin{tabular}{|c|c|c|c|}
\hline & $\begin{array}{l}\text { Unintentional } \\
\text { intoxication } \\
(n=1,776)\end{array}$ & $\begin{array}{l}\text { Intentional } \\
\text { intoxication } \\
(n=2,247)\end{array}$ & P-value \\
\hline Sex & & & $<0.001$ \\
\hline Male & $783(44.1)$ & $1,148(51.1)$ & \\
\hline Female & $993(55.9)$ & $1,099(48.9)$ & \\
\hline Age (yr) & & & $<0.001$ \\
\hline Mean \pm SD & $35.1 \pm 25.7$ & $51.8 \pm 24.7$ & \\
\hline $0-10$ & 491 (27.6) & $7(0.3)$ & \\
\hline $11-20$ & $80(4.5)$ & $107(4.8)$ & \\
\hline $21-30$ & $180(10.1)$ & $230(10.2)$ & \\
\hline $31-40$ & $215(12.1)$ & $331(14.7)$ & \\
\hline $41-50$ & 223 (12.6) & $449(20.0)$ & \\
\hline $51-60$ & $267(15.0)$ & $394(17.5)$ & \\
\hline$>60$ & $320(18.0)$ & 729 (32.4) & \\
\hline Age (yr) & & & $<0.001$ \\
\hline$\geq 65$ & $254(14.3)$ & 607 (27.0) & \\
\hline$<65$ & $1,522(85.7)$ & $1,640(73.0)$ & \\
\hline Year & & & $<0.001$ \\
\hline 2013 & 309 (17.4) & $628(27.9)$ & \\
\hline 2014 & $474(26.7)$ & $608(27.1)$ & \\
\hline 2015 & $481(27.1)$ & $536(23.9)$ & \\
\hline 2016 & $512(28.8)$ & $475(21.1)$ & \\
\hline Month & & & 0.166 \\
\hline January & $122(6.9)$ & $132(2.9)$ & \\
\hline February & $113(6.4)$ & $165(7.3)$ & \\
\hline March & $159(9.0)$ & $205(9.1)$ & \\
\hline April & $177(10.0)$ & 206 (9.2) & \\
\hline May & $199(11.2)$ & 220 (9.8) & \\
\hline June & $184(10.4)$ & $226(10.1)$ & \\
\hline July & $142(8.0)$ & $221(9.8)$ & \\
\hline August & $157(8.8)$ & 217 (9.7) & \\
\hline September & $171(9.6)$ & 178 (7.9) & \\
\hline October & $125(7.0)$ & $179(8.0)$ & \\
\hline November & $109(6.1)$ & $154(6.9)$ & \\
\hline December & 118 (6.6) & $144(6.4)$ & \\
\hline Season & & & 0.842 \\
\hline Spring to summer & 1,018 (57.3) & $1,295(57.6)$ & \\
\hline Fall to winter & 758 (42.7) & $952(42.4)$ & \\
\hline Day & & & 0.029 \\
\hline Sunday & 317 (17.8) & $322(14.3)$ & \\
\hline Monday & 234 (13.2) & $323(14.4)$ & \\
\hline Tuesday & $228(12.8)$ & 337 (15.0) & \\
\hline Wednesday & $221(12.4)$ & $310(13.8)$ & \\
\hline Thursday & $265(14.9)$ & $315(14.0)$ & \\
\hline Friday & 235 (13.2) & 291 (13.0) & \\
\hline Saturday & $276(15.5)$ & $349(15.5)$ & \\
\hline Day & & & 0.017 \\
\hline Weekday & $1,183(66.6)$ & $1,576(70.1)$ & \\
\hline Weekend & 593 (33.4) & 671 (29.9) & \\
\hline
\end{tabular}

Table 1. Continued

\begin{tabular}{|c|c|c|c|}
\hline & $\begin{array}{c}\text { Unintentional } \\
\text { intoxication } \\
(n=1,776)\end{array}$ & $\begin{array}{l}\text { Intentional } \\
\text { intoxication } \\
(n=2,247)\end{array}$ & P-value \\
\hline Blood alcohol content & & & $<0.001$ \\
\hline Positive & $167(9.4)$ & $1,081(48.1)$ & \\
\hline Negative & 1,609 (90.6) & $1,166(51.9)$ & \\
\hline Smoking & & & $<0.001$ \\
\hline Yes & $421(23.7)$ & $978(43.5)$ & \\
\hline No & $1,355(76.3)$ & $1,269(56.5)$ & \\
\hline Physical disease & & & $<0.001$ \\
\hline Yes & $348(19.6)$ & $773(34.4)$ & \\
\hline No & $1,428(80.4)$ & $1,474(65.6)$ & \\
\hline Cancer disease & & & 0.001 \\
\hline Yes & $26(1.5)$ & $70(3.1)$ & \\
\hline No & $1,750(98.5)$ & 2,177 (96.9) & \\
\hline Psychiatric disease & & & $<0.001$ \\
\hline Yes & $250(14.1)$ & 581 (25.9) & \\
\hline No & $1,526(85.9)$ & $1,666(74.1)$ & \\
\hline PSS & & & $<0.001$ \\
\hline 0 & $1,251(70.4)$ & $714(31.8)$ & \\
\hline 1 & $205(11.6)$ & $431(19.2)$ & \\
\hline 2 & $202(11.4)$ & $584(26.0)$ & \\
\hline 3 & $110(6.2)$ & $500(22.3)$ & \\
\hline 4 & $8(0.5)$ & $18(0.8)$ & \\
\hline PSS & & & $<0.001$ \\
\hline$<3$ & 1,658 (93.3) & $1,729(76.9)$ & \\
\hline$\geq 3$ & 118 (6.6) & 518 (23.0) & \\
\hline Therapeutic adherence & & & $<0.001$ \\
\hline Good & $1,600(90.1)$ & $1,891(84.2)$ & \\
\hline Poor & 176 (9.9) & 356 (15.8) & \\
\hline Type of intoxicants & & & $<0.001$ \\
\hline Pesticides & $307(17.3)$ & $1,181(52.5)$ & \\
\hline Non-prescriptives & $106(6.0)$ & 230 (10.2) & \\
\hline Prescriptives & $472(26.6)$ & $623(27.7)$ & \\
\hline Household chemicals & $396(22.3)$ & $108(4.8)$ & \\
\hline Industrial chemicals & $154(8.7)$ & $27(1.2)$ & \\
\hline Inhalations & 199 (11.2) & $60(2.7)$ & \\
\hline Plants & $142(8.0)$ & $18(0.8)$ & \\
\hline
\end{tabular}

Values are presented as number (\%) unless otherwise indicated. SD, standard deviation; PSS, poisoning severity score.

( $\geq 65$ years old), intentional intoxication risk increased from $42.0 \%$ to $65.0 \%$ (about 1.54 times greater [group 3]); for patients $<65$ years old, the intentional intoxication risk decreased to $35.4 \%$ (about 1.18 times lower). Among patients with no alcohol consumption and patients $<65$ years old, psychiatric disease was selected as the third splitting variable. With a history of psychiatric disease, the intentional intoxication risk increased from 35.4\% to $54.2 \%$ (about 1.53 times greater [group 4]); otherwise, it decreased to $31.0 \%$ (about 1.14 times lower). Among patients $<65$ years old, with no alcohol consumption and with no psychiatric 


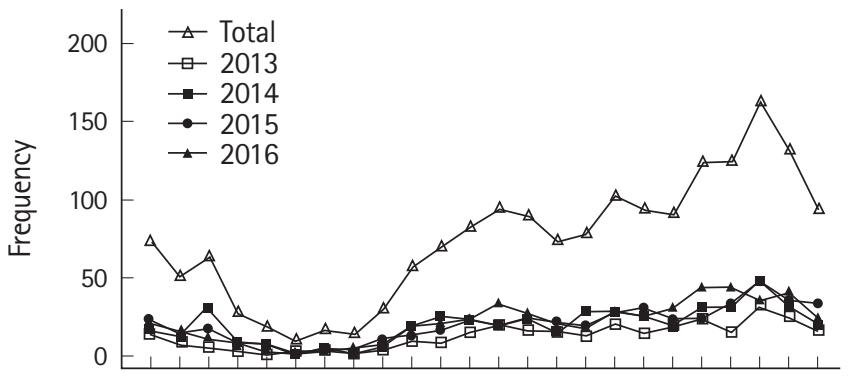

1234566789101112131415161718192021222324 Time of day (hour)

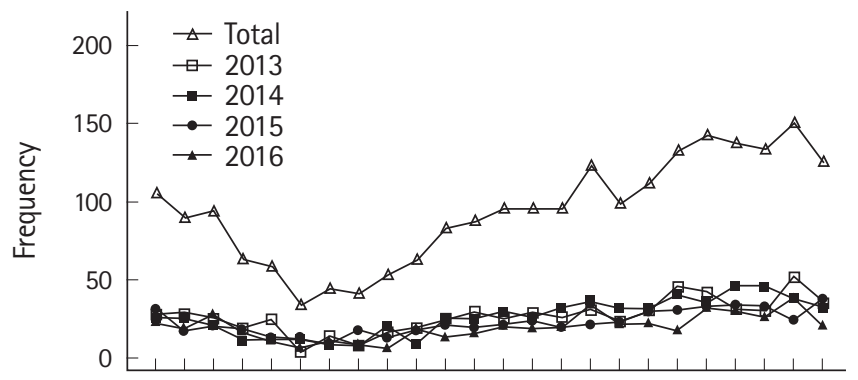

123456789101112131415161718192021222324

Time of day (hour)

Fig. 1. Diurnal variations of unintentional (A) and intentional (B) intoxication.
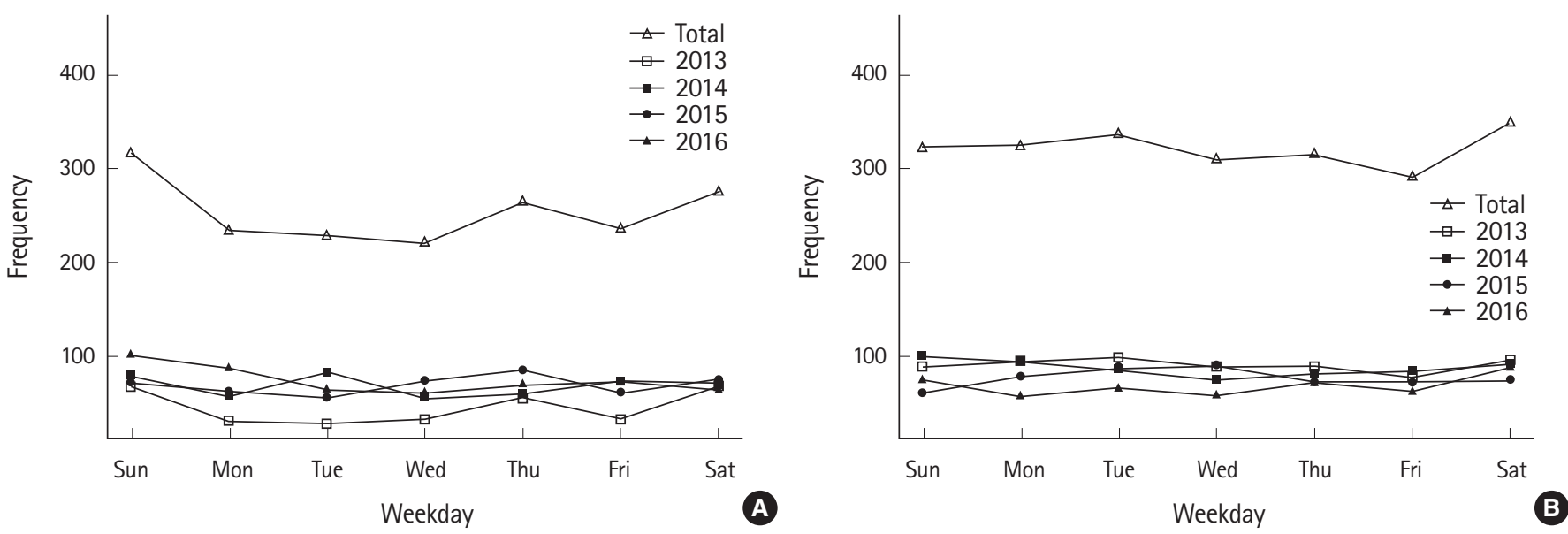

Fig. 2. Weekly variations of unintentional (A) and intentional (B) intoxication.
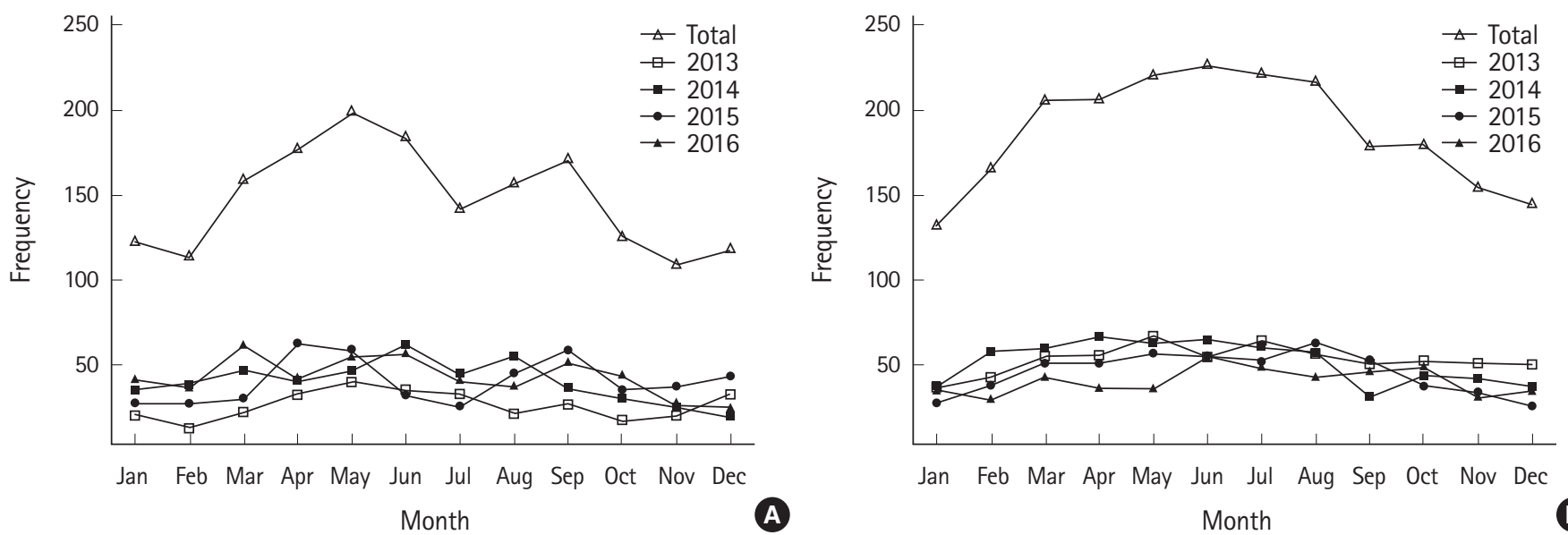

Fig. 3. Monthly variations of unintentional (A) and intentional (B) intoxication.

disease history, smoking was selected as the fourth splitting variable. For smokers, intentional intoxication risk increased from $31.0 \%$ to $44.8 \%$ (about 1.44 times greater) whereas for nonsmokers, it decreased to $25.7 \%$ (about 1.21 times lower [group 6]). Among patients $<65$ years old, those with no alcohol consump- tion, no psychiatric disease history, and those who were smokers, male sex was selected as the fifth splitting variable. Among males, the intentional intoxication risk increased from $44.8 \%$ to 70.0\% (about 1.56 times greater [group 2]) whereas for female patients, this risk decreased to 36.5\% (about 1.23 times lower 
Table 2. Annual comparison of types of intoxicant

\begin{tabular}{lccccc}
\hline Type of intoxicants & 2013 & 2014 & 2015 & 2016 & $\begin{array}{l}\text { Adjusted } \\
\text { P-valuea) }\end{array}$ \\
\hline & & & & & $<0.001$ \\
Pesticides & $448(47.8)$ & $403(37.2)$ & $333(32.7)$ & $304(30.8)$ & \\
Nonprescription drug & $81(8.6)$ & $76(7.0)$ & $100(9.8)$ & $79(8.0)$ & \\
Prescription & $187(20.0)$ & $307(28.4)$ & $296(29.1)$ & $305(30.9)$ & \\
Household chemicals & $103(10.9)$ & $117(10.8)$ & $136(13.4)$ & $148(15.0)$ & \\
Industrial chemicals & $35(3.7)$ & $41(3.8)$ & $37(3.6)$ & $68(6.9)$ & \\
Inhalations & $57(6.1)$ & $72(6.6)$ & $79(7.8)$ & $51(5.2)$ & \\
Plants & $26(2.9)$ & $66(6.1)$ & $36(3.5)$ & $32(3.2)$ &
\end{tabular}

Values are presented as number (\%)

a)Bonferroni correction.

Table 3. Results of multiple logistic regression analysis with backward stepwise elimination for prediction of intentional intoxication

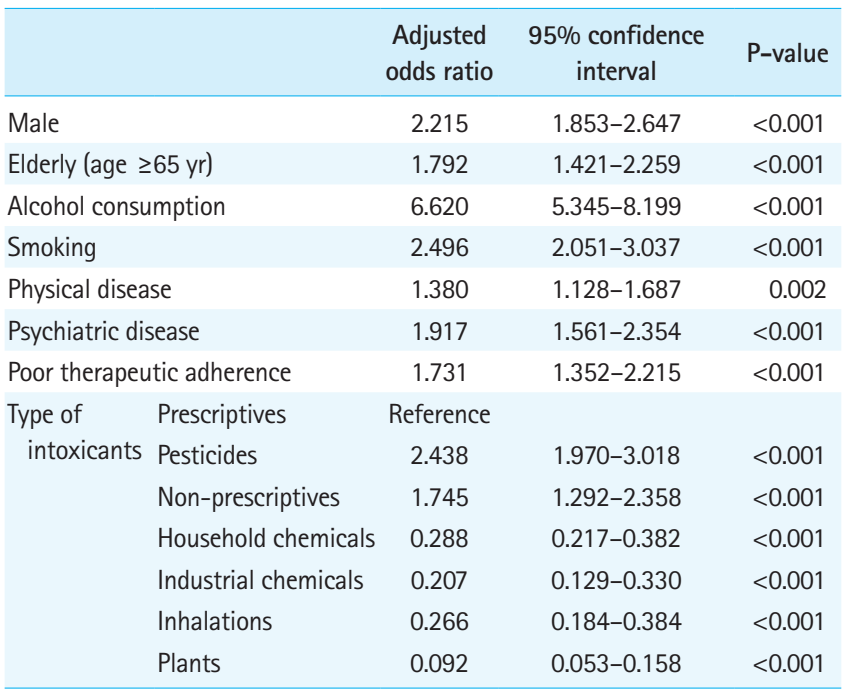

[group 5]).

The final nodes were arranged as follows: in group 1, for alcohol consumption, of the total number of patients there were 1,248 intoxication patients with an intentional intoxication risk of $86.6 \%$. Group 2 consisted of intoxication patients $<65$ years old with no alcohol consumption, no psychiatric disease, who were smokers and male, with an intentional intoxication risk of 70.0\% among 120 patients. Group 3 consisted of elderly patients with no alcohol consumption, with 65.0\% intentional intoxication risk among 615 patients. Group 4 consisted of patients $<65$ years old with no alcohol consumption who had a history of psychiatric disease, with $54.2 \%$ intentional intoxication risk among 415 patients. Group 5 included 359 female patients $<65$ years old who were smokers, with no alcohol consumption and no psychiatric disease, with an intentional intoxication risk of 36.5\%. Group 6 comprised nonsmoking patients $<65$ years old with no
Table 4. Results of multiple regression analysis with backward stepwise elimination for the predictor of poisoning severity score

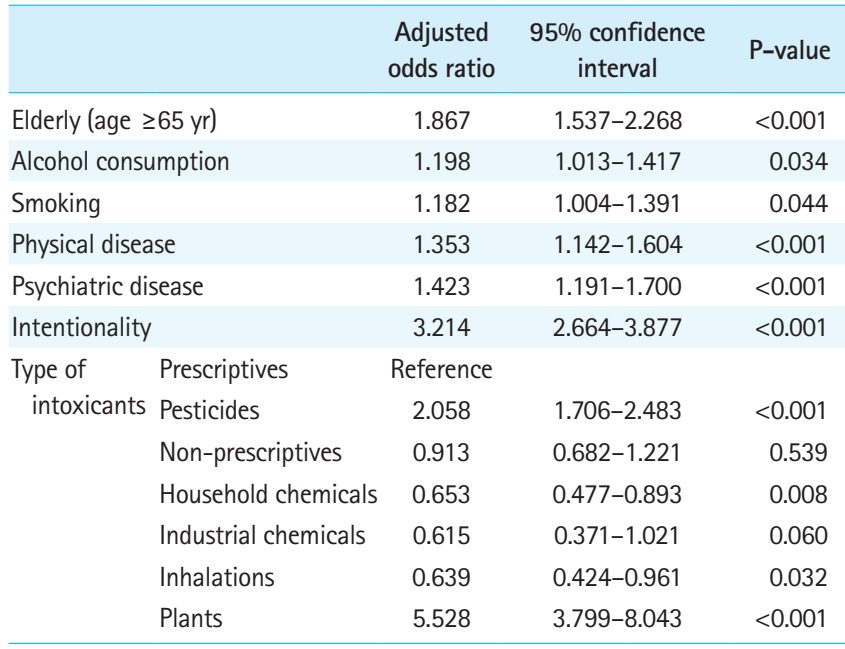

Table 5. Results of multiple regression analysis with backward stepwise elimination for predictors of poor therapeutic adherence

\begin{tabular}{|c|c|c|c|c|}
\hline & & $\begin{array}{l}\text { Adjusted } \\
\text { odds ratio }\end{array}$ & $\begin{array}{l}\text { 95\% confidence } \\
\text { interval }\end{array}$ & P-value \\
\hline \multicolumn{2}{|c|}{ Elderly (age $\geq 65$ yr) } & 0.680 & $0.518-0.891$ & 0.005 \\
\hline \multicolumn{2}{|c|}{ Alcohol consumption } & 1.265 & $1.021-1.568$ & 0.032 \\
\hline \multicolumn{2}{|c|}{ Intentionality } & 1.802 & $1.415-2.297$ & $<0.001$ \\
\hline \multirow{7}{*}{$\begin{array}{l}\text { Type of } \\
\text { intoxicants }\end{array}$} & Prescriptives & Reference & & \\
\hline & Pesticides & 0.751 & $0.586-0.964$ & 0.025 \\
\hline & Non-prescriptives & 1.600 & $1.165-2.198$ & 0.004 \\
\hline & Household chemicals & 0.919 & $0.649-1.302$ & 0.634 \\
\hline & Industrial chemicals & 0.804 & $0.461-1.401$ & 0.441 \\
\hline & Inhalations & 1.175 & $0.778-1.766$ & 0.444 \\
\hline & Plants & 1.333 & $0.807-2.203$ & 0.262 \\
\hline
\end{tabular}

alcohol consumption and no psychiatric disease, and included 1,266 patients with a risk of $25.7 \%$ (Fig. 4).

\section{DISCUSSION}

Previous statistical analyses have aimed to verify hypotheses regarding suicidal populations using sample groups; there is also a possibility of confounding bias in variables related to suicide. The representativeness of such samples, however, is limited with respect to accuracy; hence, big data or data mining analysis that analyzes census data is a possible alternative to reducing these uncertainties. ${ }^{918}$ This analysis is different from existing statistical methods, whose main purpose is to predict targets and not hypothesis verification. It is currently possible to collect massive information using data networking with a future outlook and insight suggested through data analysis of real circumstances. This 


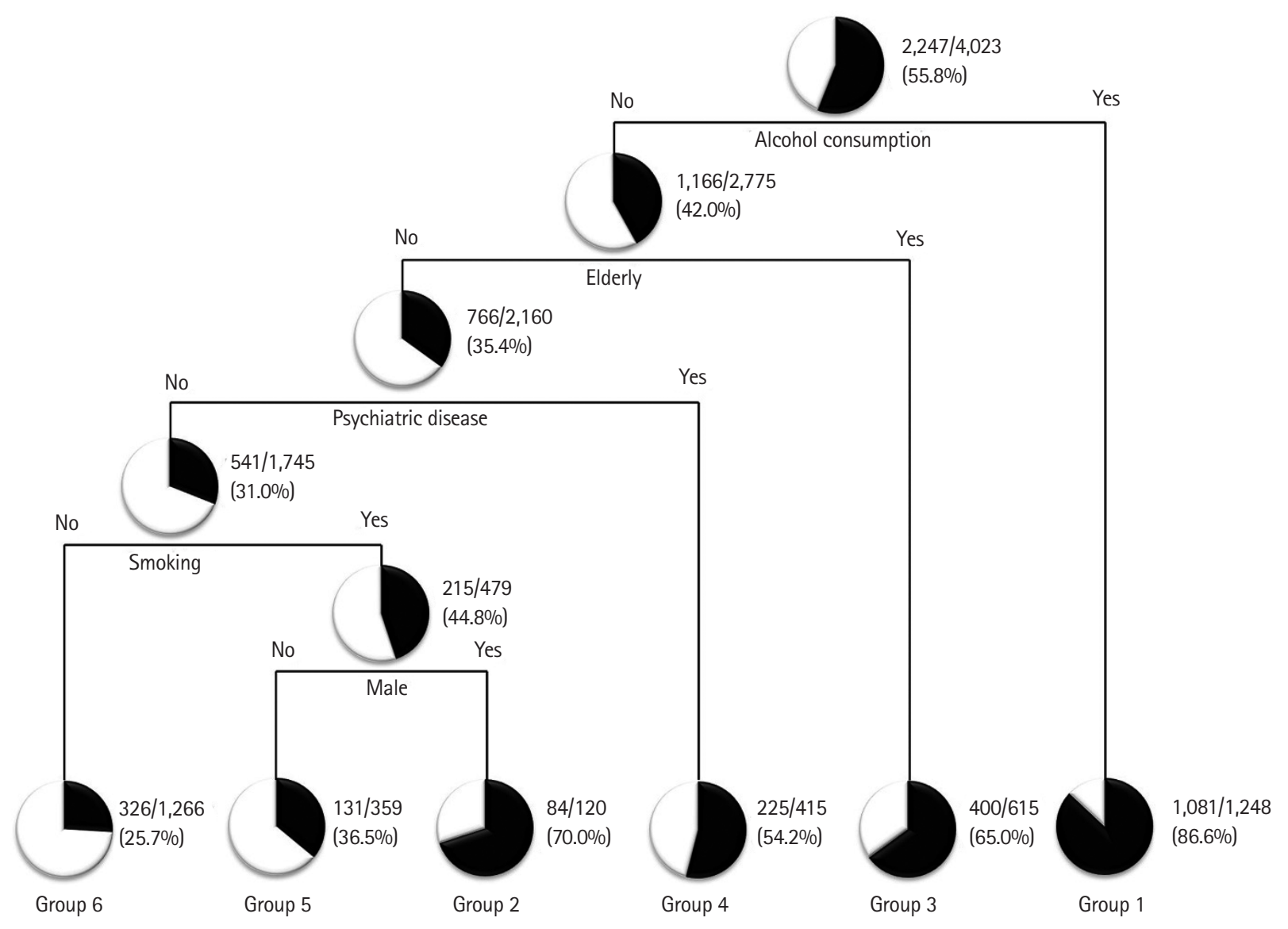

Fig. 4. Decision tree for intentional intoxication.

study used adjusted data mining analysis to select groups at risk of intentional intoxication, through targeting all patients with intoxication in the PSI. The present study provides important contributions as a pilot study, and it is the first attempt to analyze risk factors of suicide using data mining. We reveal the possibility of predicting groups at risk of attempting suicide, which offers the potential for crisis intervention among such high-risk groups.

Recent intentional intoxication rates in South Korea have reported to be about $61.0 \%$ to $77.4 \%$. These reported percentages increase with age. ${ }^{19,20}$ In this study, we found an intentional intoxication rate of 54.6\%. Excluding the age group 0 to 10 years, all age categories had high rates of intentional intoxication, with the highest among elderly people, among whom our findings were similar to those of previous studies. ${ }^{19,20}$

As mentioned, the highest rates of suicide in South Korea are among elderly people, and these are most often owing to poisoning by ingestion of pesticides. Moreover, suicide death rates are higher in farming and mountainous areas. ${ }^{17}$ In these regions, depression tends to be very common, and the population in farming and mountainous areas consists largely of elderly people. Moreover, in most cases of suicide among elderly people, familiar sui- cide methods are often selected, which may explain the high rate of intentional intoxication with pesticides among this population. ${ }^{21}$ In addition, the intentional intoxication rate has an increasing trend and poor prognosis in the elderly population compared with other age groups. ${ }^{22-24}$ In this study, elderly age was found to be a predictor of intentional intoxication risk as well as a factor for severe poisoning symptoms. Also, in this study, pesticides were the most frequent intoxicants used intentionally; this is likely because the PSI is located in a farming area and this institute has a pesticide intoxication laboratory. A high rate of intentional intoxication using pesticides is a common social phenomenon in the Asia-Pacific region. ${ }^{25,26}$ Therefore, it is clear that elderly age, living in farming or mountainous areas, and access to pesticides can be assumed to be risk factors and predictors of groups at risk for suicide. These populations require active crisis intervention that considers age group, location, and environment.

The rate of intentional intoxication with pesticides has a decreasing trend, similar to the trend in urban areas. ${ }^{22}$ According to a recent report of the National Statistical Office of South Korea, the leading cause of suicide deaths among older generations was attributed to pesticide poisoning; among younger age groups, 
hanging and jumping from a height were the most frequent causes of suicide deaths. ${ }^{17}$ It is possible that the sharp decrease in intentional intoxication and pesticide poisoning rates may have been caused by changes in suicide methods resulting from changes in economic and population structure with industrialization of local areas surrounding the PSI. Therefore, changes in the local characteristics used to predict suicide risks and for targeting prevention policies must be considered.

In previous studies, suicidal ideation and suicide attempts have been reported as more frequent among women, but the actual suicide rate is reportedly higher for men. ${ }^{27}$ According to the present study findings, male sex had a significant influence on intentional intoxication. Male sex was also a predictor of intentional intoxication in the decision tree modeling analysis.

Physical disease and cancer are also important factors that influence suicide, as previous studies have shown. ${ }^{7.28}$ In our study, physical disease and cancer were factors influencing intentional intoxication but were not predictors of risk. In follow-up studies to identify groups at high risk for suicide, it will be necessary to analyze disease information in greater detail, by considering various factors such as age, diagnosis, and disease stage.

The main limitation of this study was the small number of variables, which were insufficient to define specific groups at risk of suicide. First, there is a possibility of selection bias as the retrospective study occurred at only one local institute. Clear differences exist regarding the domestic suicide rate, suicide death rate, and suicide methods, depending on each local area. ${ }^{17,20,22} \mathrm{An}$ analysis using national and systematic data collection is required in the future, which can be used to predict high-risk groups for suicide and to establish suicide prevention policies for each local area.

Secondly, characteristics related to suicide show clear differences according to socioeconomic factors, personal/family factors, and suicide history (previous history of suicide attempts). ${ }^{1,3,5,17}$ However, because in this study we directly collected information on emergency room patients with intoxication as identified by the medical team, long-term detailed data collection was impossible owing to limited human resources. Thus, adequate manpower and database processing facilities are required for multilateral variable collection and for risk factor prediction.

Thirdly, there could be low reliability of the medical histories self-reported by patients or their guardians because of the negative image surrounding a history of psychiatric disease and the difficulty in obtaining insurance policies with diagnoses of a suicide attempt or drug overdose. ${ }^{29}$ Therefore, during the study process, we excluded some patients with a history of suicide attempts, those who denied giving answers regarding suicidal in- tention, or those who declined to respond but who were strongly suspected of attempting suicide based on the circumstances. In this study, the psychiatric disease rate among patients with intentional intoxication was $25.9 \%$. In previous studies in South Korea, the psychiatric disease rate among people with intentional intoxication was reported to be about $26.5 \%$ to $46.0 \%$; hence, previous findings are comparable to the findings of the present study. ${ }^{20,29}$

A suicide attempt is considered a clear manifestation of psychiatric disease, with suicide ideation as one criterion of a diagnosis of depression, our results reflect that more than half of intentional intoxication patients may not be diagnosed with a psychiatric disease. Also, intentional intoxication was the factor with the largest influence on poor therapeutic adherence, which implies that it may be difficult for individuals to utilize psychiatric services, even when they have a suicidal intention. Nevertheless, the findings of regression analysis in this study showed that psychiatric disease significantly influenced intentional intoxication and was a main risk factor in the decision tree model. In other words, psychiatric disease clearly influences the act of committing suicide. However, suicide prevention policies targeting only psychiatric disease would have low efficiency. To effectively reduce the suicide rate, it is necessary to predict which individuals are at risk of a suicide attempt in advance, through multilateral factor examination and pattern analysis. In this case, a decision tree model can be an appropriate method for accurate analysis. In addition, to effectively track the management of patients who attempt suicide, there should be standardized evaluations of psychiatric risk factors, and treatment guidelines must be developed and distributed for people who attempt suicide as the primary targets, as well as their guardians.

In summary, intentional intoxication was found to be the strongest predictor of severe poisoning symptoms and poor therapeutic adherence whereas use of pesticides as an intoxicant presented the closest association with intentional intoxication. In order of importance, intentional intoxication is influenced by alcohol consumption, smoking, male sex, psychiatric disease, elderly age, poor therapeutic adherence, and physical disease. Moreover, elderly age, psychiatric disease, smoking, and male sex are the main factors that predict groups at risk of intentional intoxication. As realistically as possible, crisis intervention aimed at preventing suicide among these specific high-risk groups is necessary. To achieve this, an analytic approach with broad data collection and possible segmentation that is based on actual suicide patient groups, and with use of the decision tree model analysis technique, can be considered a complementary method. 


\section{CONFLICT OF INTEREST}

No potential conflict of interest relevant to this article was reported.

\section{ACKNOWLEDGMENTS}

This work was supported by the Soonchunhyang University Research Fund.

\section{REFERENCES}

1. Stewart SE, Manion IG, Davidson S, Cloutier P. Suicidal children and adolescents with first emergency room presentations: predictors of six-month outcome. J Am Acad Child Adolesc Psychiatry 2001;40:580-7.

2. Cerel J, Jordan JR, Duberstein PR. The impact of suicide on the family. Crisis 2008;29:38-44.

3. Steele IH, Thrower N, Noroian P, Saleh FM. Understanding suicide across the lifespan: a United States perspective of suicide risk factors, assessment \& management. J Forensic Sci 2018;63:162-71.

4. World Health Organization. Public health action for the prevention of suicide: a framework. Geneva: World Health Organization; 2012.

5. Wasserman D. Suicide: an unnecessary death. London: Oxford University Press; 2016.

6. Nock MK, Borges G, Bromet E, et al. Cross-national prevalence and risk factors for suicidal ideation, plans and attempts. $\mathrm{Br} J$ Psychiatry 2008;192:98-105.

7. Choi SB, Lee W, Yoon JH, Won JU, Kim DW. Risk factors of suicide attempt among people with suicidal ideation in South Korea: a cross-sectional study. BMC Public Health 2017;17: 579.

8. Borges G, Nock MK, Haro Abad JM, et al. Twelve-month prevalence of and risk factors for suicide attempts in the World Health Organization World Mental Health Surveys. J Clin Psychiatry 2010;71:1617-28.

9. Linden A, Yarnold PR. Using data mining techniques to characterize participation in observational studies. J Eval Clin Pract 2016;22:835-43.

10. Tseng WT, Chiang WF, Liu SY, Roan J, Lin CN. The application of data mining techniques to oral cancer prognosis. J Med Syst 2015;39:59.

11. Bang $\mathrm{S}$, Son $\mathrm{S}$, Roh $\mathrm{H}$, et al. Quad-phased data mining modeling for dementia diagnosis. BMC Med Inform Decis Mak 2017; 17(Suppl 1):60.
12. Song YY, Lu Y. Decision tree methods: applications for classification and prediction. Shanghai Arch Psychiatry 2015;27: 130-5.

13. Crawford MJ, Wessely S. Does initial management affect the rate of repetition of deliberate self harm? Cohort study. BMJ 1998;317:985.

14. Kim DK, Chun BJ, Moon JM, et al. Contributing factors for the registration rates within emergency department based postsuicidal care program. J Korean Soc Clin Toxicol 2016;14:54-9.

15. Cook R, Allcock $R$, Johnston M. Self-poisoning: current trends and practice in a U.K. teaching hospital. Clin Med (Lond) 2008; 8:37-40.

16. Schwake L, Wollenschlager I, Stremmel W, Encke J. Adverse drug reactions and deliberate self-poisoning as cause of admission to the intensive care unit: a 1-year prospective observational cohort study. Intensive Care Med 2009;35:266-74.

17. Song TM, Jin DL, Song JY, Ahn JY, Cho YH. A comparative analysis of suicide characteristics by age group in Korea. J Korea Soc Health Inf Stat 2013:122-42.

18. Gandomi A, Haider M. Beyond the hype: big data concepts, methods, and analytics. Int J Inf Manag 2015;35:137-44.

19. So BH, Lee MJ, Kim H, et al. 2008 Database of Korean toxic exposures: a preliminary study. J Korean Soc Clin Toxicol 2010; 8:51-60.

20. Ko SH, Lee KW. Clinical analysis of acute drug poisoning victims by intentional poisoning. J Korean Soc Emerg Med 2012; 23:679-86.

21. Bronstein AC, Spyker DA, Cantilena LR Jr, Green JL, Rumack BH, Dart RC. 2010 Annual report of the American Association of Poison Control Centers' National Poison Data System (NPDS): 28th annual report. Clin Toxicol (Phila) 2011;49:910-41.

22. Kong SK, Oh SH, Park KN, Kim HJ. Trends of intentional poisoning: a retrospective single center study during 15 years. $J$ Korean Soc Clin Toxicol 2016;14:47-53.

23. Muhlberg W, Becher K, Heppner HJ, Wicklein S, Sieber C. Acute poisoning in old and very old patients: a longitudinal retrospective study of 5883 patients in a toxicological intensive care unit. Z Gerontol Geriatr 2005;38:182-9.

24. Lee WJ, Choi SM, Kyong YY, et al. Clinical analysis of acute poisoning in elderly patients. J Korean Geriatr Soc 2009;13: 24-30.

25. Eddleston $M$, Gunnell D, Karunaratne A, de Silva D, Sheriff $\mathrm{MH}$, Buckley NA. Epidemiology of intentional self-poisoning in rural Sri Lanka. Br J Psychiatry 2005;187:583-4.

26. Eddleston M, Phillips MR. Self poisoning with pesticides. BMJ 2004;328:42-4.

27. Canetto SS, Sakinofsky I. The gender paradox in suicide. Sui- 
cide Life Threat Behav 1998;28:1-23.

28. Ahmedani BK, Peterson EL, Hu Y, et al. Major physical health conditions and risk of suicide. Am J Prev Med 2017;53:308-15.
29. Kim HJ, Kim HM, Kim HJ, et al. Association of prescribed drug intoxication and neuropsychiatric history. J Korean Soc Clin Toxicol 2011;9:77-80. 